\title{
DEFINIÇÃO ESTRATIGRÁFICA DA FORMAÇÃO MISSÃO VELHA, BACIA DO ARARIPE
}

\subsection{0/1980-8208/estudosgeologicos.v30n2p3-25}

\author{
Aerson Moreira Barreto Junior ${ }^{1}$ \\ Gelson Luís Fambrini ${ }^{2}$ \\ Wellington Ferreira da Silva Filho ${ }^{3}$ \\ Diego da Cunha Silvestre ${ }^{1}$
}

${ }^{1}$ Pós-Graduação em Geociências PPGEOC-UFPE (aerson@ hotmail.com, diiegocs@ hotmail.com)

2Departamento de Geologia-UFPE (gelson.fambrini@ufpe.br, virginio.neumann@ufpe.br)

${ }^{3}$ Departamento de Geologia-UFC (welfer@ufc.br)

\section{RESUMO}

A Formação Missão Velha corresponde aos depósitos fluviais do intervalo NeojurássicoEocretáceo na Bacia do Araripe, depositada no contexto da Depressão Afro-Brasileira no Início de Rifte do Gondwana Ocidental. A Formação Missão Velha destaca-se com relação às demais unidades da Bacia do Araripe, sobretudo, pela ocorrência de uma assembleia fossilífera de troncos silicificados de coníferas. Embora os depósitos da Formação Missão Velha e das outras unidades do Andar Dom João nas demais bacias interiores do Nordeste de modo geral não apresentem feições diagnósticas de tectonismo e magmatismo ativo, uma série de investigações na última década desafiaram a obviedade em busca do entendimento das condições do início do rifte através de novos métodos comparativos e interpretativos. Tendo em vista estes recentes avanços e observando a necessidade de uma revisão da unidade à luz desses novos dados, a fim de facilitar a comunicação entre os autores, o presente trabalho determina de forma objetiva através da análise da evolução de conhecimentos e delimitação, condições tectonoestratigráficas, a caracterização geológica e paleontológica da Formação Missão Velha. Concluiu-se que a unidade apresenta uma discordância interna e que suas sequências inferior e superior apresentam distinção de sentido de paleocorrentes que mudam de prioritariamente S-SE para NW; associação de fácies que mudam de depósitos fluviais com planícies de inundação intercaladas para depósitos de fundo de canal de alta energia com presença de troncos silicificados. Por sua vez, a atribuição dos troncos ao táxon Dadoxylon-Araucarioxylon deve ser desencorajada pois estão em desacordo com o Código Internacional de Nomenclatura Botânica.

Palavras-chave: Bacia do Araripe, Andar Dom João, Formação Missão Velha.

\section{ABSTRACT}

The Missão Velha Formation corresponds to the fluvial deposits through the Jurassic-Cretaceous interval in the Araripe Basin, deposited under the context of the Afro-Brazilian Depression in the West Gondwana Early Rift Stage. The Missão Velha Formation stands out in the Araripe Basin mainly due to the occurrence of an assembly of silicified coniferous trunks. Although the Missão Velha Formation and the Dom João Stage deposits, in general, do not present diagnostic features of tectonism and active magmatism, a series of investigations in the last decade challenged the obviousness, seeking to understand the conditions of the early rift, through new comparative and interpretative methods. Under the sight of these new data and in order to facilitate communication between the authors, the present work proposes an objective delimitation and definition of the unit through the analysis of its state of the art and delimitation, tectonoestratigraphic conditions, and its geological and paleontological settings. The unit presents an internal unconformity and its lower and upper sequences present a distinction in the paleocurrents patterns that change from S-SE to 
NW, respectively; the facies association change from riverbeds with interdigitated floodplain deposits to high-energy braided channels deposits with the presence of silicified trunks. The assignment of the silicified trunks to the Dadoxylon-Araucarioxylon taxon should be discouraged, since this denomination is outdated accordingly the rules of the International Code of Botanical Nomenclature.

Keywords: Araripe Basin, Dom João Stage, Missão Velha Formation.

\section{INTRODUÇÃO}

Um dos intervalos mais interessantes, importantes e exclusivos das bacias do Nordeste do Brasil é o intervalo Neojurássico-Eocretáceo, que inclui as formações Brejo Santo e Missão Velha na Bacia do Araripe (Ponte \& Asmus, 1976, 1978; Assine, 1992; Ponte \& Ponte Filho, 1996; Assine, 2007; Fambrini et al., 2007, 2008, 2009, 2010b, c, 2011, 2013a, b, c, 2017, 2019). Neste intervalo destacam-se os arenitos da Formação Missão Velha por serem importantes rochas aquífero, e por terem correlatos nas demais bacias do Nordeste do Brasil, tais como a Formação Serraria na Bacia Sergipe; a Formação Sergi nas bacias do Recôncavo-Tucano-Jatobá e Camamu-Almada (Da Rosa \& Garcia, 2000; Kuchle et al., 2011; Fambrini et al., 2011, 2017, 2019).

A Bacia do Araripe constitui-se na mais completa e complexa das bacias interiores do NE do Brasil (Fig. 1). A origem e a evolução da Bacia do Araripe relacionam-se com os eventos tectônicos que resultaram na ruptura e fragmentação do Supercontinente Gondwana e na abertura do Oceano Atlântico Sul (Asmus \& Ponte, 1973; Ponte \& Asmus, 1976, 1978; Ponte \& Ponte Filho, 1996; Matos, 1999; Assine, 2007; Fambrini et al., 2007, 2008, 2009, 2010a, b). A bacia assentase sobre terrenos pré-cambrianos da Zona Transversal da Província Borborema (Brito Neves et al., 2000; Santos et al., 2004; BritoNeves et al., 2016) ao sul da Zona de Cisalhamento de Patos, compostos por rochas metamórficas variadas e plútons graníticos. A Bacia do Araripe apresenta estruturação segundo as direções NE-SW (predominantemente falhas normais) a E-W (predominantemente falhas transcorrentes) e, subordinadamente, NW-SE (falhas transcorrentes e normais), coincidentes com descontinuidades do embasamento précambriano, reaproveitadas para a instalação da bacia (Matos, 1992, 1999). O empilhamento sedimentar comporta quatro tectono-sequiências deposicionais redefinidas por Fambrini et al. (2010a, 2011, 2017, 2019) em base aos trabalhos de Prosser (1993) e de Almeida et al. (2009): (i) Sequência Paleozoica, constituída pela Formação Cariri representada por arenitos médios a grossos fluviais, de idade neordoviciana a eossiluriana; (ii) Sequência Início de Rifte, de idade neojurássica, composta pelos pelitos da Formação Brejo Santo e pelos arenitos da porção inferior da Formação Missão Velha; (iii) Sequência Clímax de Rifte, constituída pelos arenitos grossos da porção superior da Formação Missão Velha e pelos pelitos e arenitos da Formação Abaiara, de idade neocomiana. (iv) Sequência pós-rifte, separada em duas, Pós-Rifte I, de idade aptiano-albiana, constituída pelas formações Barbalha, Crato, Ipubi e Romualdo, e PósRifte II, de idade albiano-cenomaniana, achase caracterizada por sedimentos aluviais das formações Araripina e Exu.

A Bacia do Araripe, sendo amplamente conhecida por sua grande variedade de ocorrências fósseis - especificamente de peixes, insetos, e pterossauros no Grupo Santana (sensu Neumann, 1999; Assine et al., 2014; Fambrini et al., 2017, 2019), vem sendo objeto de numerosas publicações na última metade de século (Chagas, 2006). A Formação Missão Velha (Ponte \& Appi, 1990) destaca-se na bacia sobretudo pela ocorrência de uma assembleia fossilífera de troncos silicificados de coníferas. Embora os depósitos da Formação Missão Velha e do Andar Dom João de modo geral não apresentem feições diagnósticas de tectonismo e magmatismo ativo, uma série de 
investigações na última década desafiaram a obviedade em busca do entendimento das condições do início do rifte através de novos métodos comparativos e interpretativos (e.g. Freitas et al., 2008; Fambrini et al., 2010a,
2011; Pires \& Guerra-Sommer, 2011; Fambrini et al., 2013b, c Costa et al., 2014; Scherer et al., 2014; Fambrini et al., 2017, 2019).

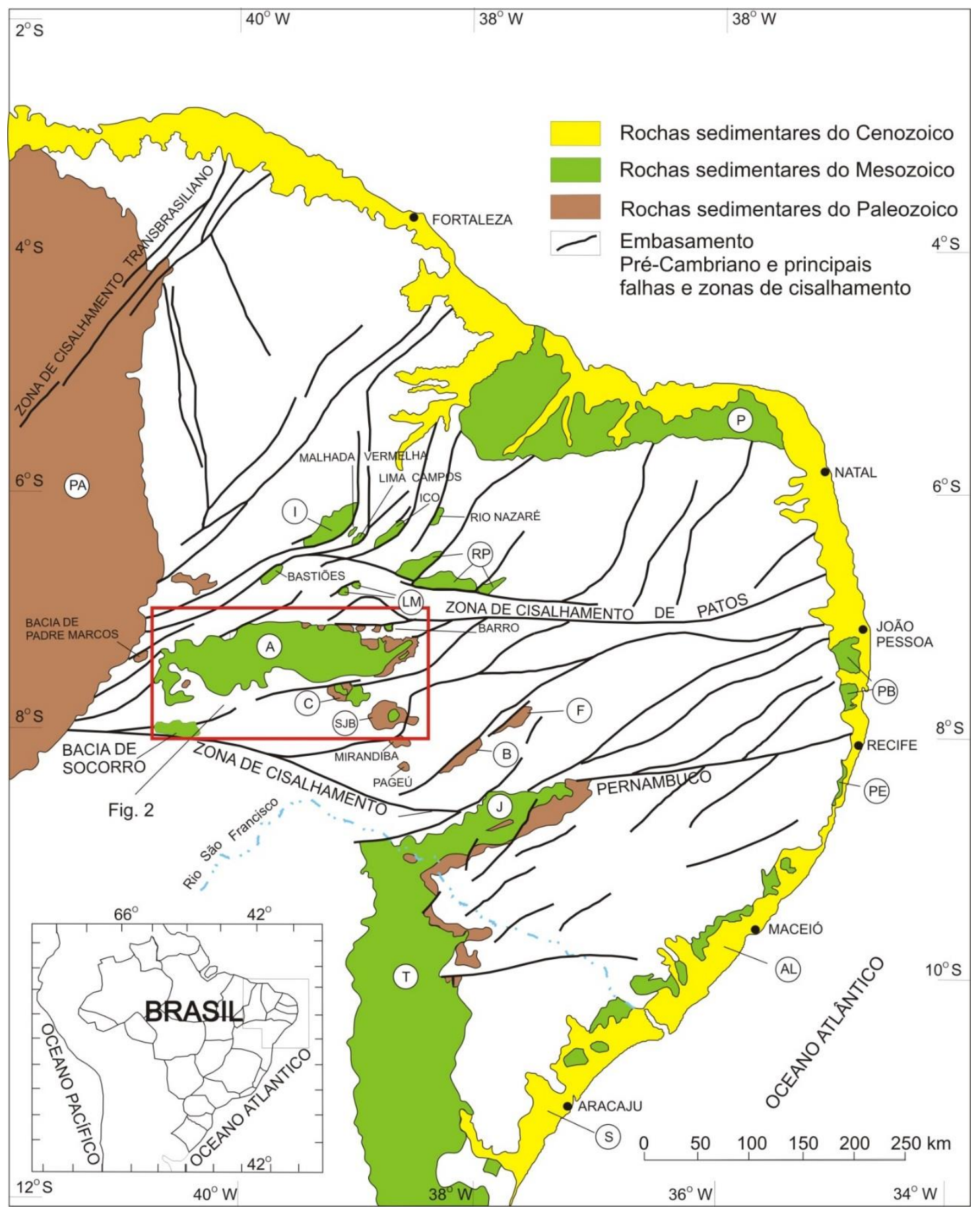

Figura 1 - Esquema das bacias fanerozoicas da região nordeste do Brasil com destaque para as bacias interiores das quais a Bacia do Araripe (no destaque) toma parte. Legenda: $(\mathrm{A}=$ Araripe; Brasil, com a Bacia do Araripe em destaque (A = Araripe; AL: Alagoas; B: Betânia; C: Cedro; F: Fátima; IG = Iguatu; J = Jatobá; LM: Lavras da Mangabeira; P = Potiguar; PB: Paraíba; PE: Pernambuco; RP = Rio do Peixe; SA = Sergipe-Alagoas; SJB: São José do Belmonte; SE: Sergipe; $\mathrm{T}=$ Tucano) (modificado de Assine, 1992; Fambrini et al., 2011). 
Tendo em vista estes recentes avanços faz-se necessária uma melhor definição da Formação Missão Velha à luz desses novos dados, a fim de manter a bibliografia da Bacia do Araripe atualizada e integrada, facilitando a comunicação entre autores e contribuindo para futuros trabalhos na unidade. Deste modo, o presente trabalho propõe uma delimitação e definição objetivas da unidade através da análise de sua evolução de conhecimentos e delimitação da unidade, condições tectonoestratigráficas, caracterização geológica e paleontológica.

\section{EVOLUÇÃO DE CONHECIMENTOS E DELIMITAÇÃO DA UNIDADE}

\section{Primeiros registros (1859 a 1861)}

Ainda que as primeiras descrições que mencionam a litoestratigrafia da Bacia do Araripe remontem às expedições de Gardner em 1838, a primeira menção aos arenitos da Formação Missão Velha apareceriam nos diários da Comissão Científica de Exploração, que estudou os recursos geológicos, botânicos, faunísticos e etnográficos da Província do Ceará entre 1859 e 1861 (Alemão \& Alemão, 1862). O cronista daquela viagem e poeta notável da literatura brasileira, Antônio Gonçalves Dias, foi o primeiro a reportar a existência de arenitos portadores de "madeira petrificada" na localidade de São Pedro, situada entre as vilas de Crato e Milagres (Sousa-Brasil, 1863; Hartt \& Agassiz, 1870).

\section{Primórdios da estratigrafia na Bacia do Araripe (1879 a 1913)}

Através de revisão bibliográfica das bacias interiores, Branner (1890) propõe uma correlação estratigráfica, ainda que precária, dos depósitos das bacias Sergipe-Alagoas, Araripe e Tucano-Jatobá, sugerindo que estas fizeram parte de uma única bacia em algum momento no passado devido à sua similaridade em sucessões sedimentares e conteúdo fossilífero. Neste trabalho o autor mencionaria extensamente as pesquisas de
Derby (1879), que descreveu a existência de afloramentos de arenitos e conglomerados portadores de madeira silicificada entre Piranhas e Tacaratu, em Pernambuco.

Small (1913) realizaria a primeira descrição da coluna estratigráfica do Araripe, dividindo-a em quatro unidades: Conglomerado Basal, Arenito Inferior, Calcário Santanna e Arenito Superior, sendo esta subdivisão utilizada durante toda a primeira metade do Século XX.

\section{Definição da unidade (1962 a 1984)}

Na década de 1960, a litoestratigrafia do Araripe fora revista e suas pesquisas foram intensificadas, patrocinadas por organismos e entidades federais (e.g. UFPE, SUDENE, DNPM e Petrobras). Com a crescente influência da formalização estratigráfica proposta pelo Código NorteAmericano de Nomenclatura Estratigráfica (ACSN, 1961), o termo Formação Missão Velha foi introduzido por Beurlen (1962, 1963) para englobar todo o pacote siliciclástico abaixo do Calcário Santana, correlativo ao "Arenito Inferior" de Small (1913). Sobre a Formação Missão Velha, Beurlen $(1962,1963)$ discriminou as áreas de ocorrência, composição litológica, variações de fácies e notou a presença abundante de troncos fósseis nos arenitos da unidade. Nesta concepção, a Formação Missão Velha incluía na porção inferior arenitos com estratificações cruzadas; na porção mediana adviriam intercalações de camadas pelíticas (argilitos, folhelhos, siltitos e arenitos finos de coloração esverdeada a cinzenta) e, por fim, na porção superior, apareceriam arenitos com intercalações de conglomerados, propondo-se idade neocomiana aos depósitos. Assim, a unidade teria abrangência estratigráfica muito ampla o que motivou diversas revisões da unidade nos anos seguintes.

Gaspary \& Anjos (1964) limitaram a definição de Formação Missão Velha à parte arenosa superior da concepção original de Beurlen (1962, 1963) por meio do desmembramento da seção basal pelítica. Os 
pelitos basais foram denominados pelos autores de Formação Brejo Santo, restringindo assim a concepção original de Beurlen (1962, 1963). De acordo com esta nova proposição os autores situaram cronoestratigraficamente ambas unidades no Jurássico Superior.

Braun (1966) correlacionou a Formação Missão Velha à Formação Sergi do Grupo Brotas, unidade correlata das bacias do Recôncavo, Tucano e Jatobá. Deste modo, os pelitos basais relacionados à Formação Brejo Santo por Gaspary \& Anjos (1964) foram correlacionados à Formação Aliança do mesmo grupo. Com isso, Braun restringiu assim ainda mais a abrangência desta unidade litoestratigráfica. No entanto, ao perpetrar tal correlação, o autor não percebeu que, através desta relação com as formações Aliança e Sergi, eliminou toda a parte superior da Formação Missão Velha, conforme originalmente sugerida por Small (1913) e formalmente proposta por Beurlen (1962). Esta proposição estratigráfica foi seguida por Mabesoone \& Tinoco (1973), Lima (1978, 1979) e Silva (1983, 1986).

Moraes et al. (1976) propuseram a divisão do "Arenito Inferior" de Small (1913) em duas unidades informais: Unidade Inferior e Fácies Arenosa. Para a Unidade Inferior os autores incluíram espesso pacote de arenitos com troncos silicificados e ocasionais intercalações de siltitos e folhelhos. $\mathrm{O}$ conjunto foi colocado estratigraficamente no Neocomiano. A Fácies Arenosa foi definida como constituída por arenitos com inúmeras intercalações de folhelhos, siltitos, margas betuminosas, calcarenitos e conglomerado calcífero, sendo pertencente ao Aptiano Inferior. Os autores consideraram estas unidades como análogas das formações Missão Velha de Beurlen (1963) e Sergi de Braun (1966). No entanto, estas unidades não são equivalentes estratigraficamente analisando-se as definições originais. A Formação Sergi corresponde à parte superior da Formação Missão Velha, pois a porção inferior pelítica foi denominada de Formação Aliança, conforme o trabalho de Braun (1966).

\section{Formalização da Bacia do Araripe (1986 a 1999)}

Proposições modificadoras da coluna litoestratigráfica da Bacia do Araripe e, em especial, da Formação Missão Velha, somente ocorreriam no final da década de 1980 (e.g. Ghignone et al., 1986; Berthou et al., 1988; Viana \& Cavalcanti, 1989) e, principalmente, no início da década de 1990 (e.g. Ponte et al., 1990; Berthou, 1990; Cavalcanti \& Viana, 1992; Ponte \& Appi, 1990; Assine, 1990, 1992; Martill, 1993) por ocasião do Primeiro Simpósio sobre a Bacia do Araripe e Bacias Interiores do Nordeste, realizado na cidade do Crato em 1990, as pesquisas sobre a Bacia do Araripe tomaram enorme impulso. Dentre estas propostas merecem destaque as formuladas por Ghignone et al. (1986), Ponte \& Appi (1990) e Assine (1992), nas quais o panorama litoestratigráfico atual da bacia se baseia, como será visto.

No que tange à Formação Missão Velha, Ponte \& Appi (1990) separaram em três unidades o conjunto de arenitos e, subordinadamente, conglomerados e pelitos sobrejacentes à Formação Brejo Santo. Para a porção inferior mantiveram a denominação tradicional Formação Missão Velha ao se referirem aos arenitos grossos portadores de troncos e madeira fósseis silicificados posicionando-os no Andar Dom João. Para a parte intermediária atribuíram a denominação Formação Abaiara para reunir sucessão de arenitos finos a médios com intercalações de siltitos e folhelhos que apresentam ostracodes fósseis típicos das biozonas indicativas dos andares Rio da Serra/Aratu, ou seja, do Neocomiano. Para o topo da unidade designaram de Formação Rio da Batateira ao conjunto sedimentar constituído por arenitos médios a finos intercalados com folhelhos negros a cinza, onde se destaca nível delgado de folhelho betuminoso (Camadas Batateira de Hashimoto et al., 1987). Esta unidade foi posicionada no Andar Alagoas (Aptiano Superior) através de datações por polens e ostracodes. 
Conforme discutido por Assine (1990, 1992), o contato entre as formações Brejo Santo e Missão Velha é concordante, assinalado por uma passagem gradual de fácies pelíticas avermelhadas para fácies psamíticas sobrepostas, que denotam pouca variação granulométrica na vertical, ilustrada pelo padrão em caixa observado no intervalo 837 a $1.023 \mathrm{~m}$ do poço estratigráfico 2-AR-1CE. Deste modo, a Formação Missão Velha, na concepção de Assine (1992), comportaria arenitos finos na base que gradam para arenitos médios até grossos nos estratos superiores, cuja espessura é de cerca de $200 \mathrm{~m}$, mantendo-se constante ao longo da bacia. Tal homogeneidade litológica, de acordo com o autor, é também observada na área de afloramentos ao longo do Vale do Cariri, onde a unidade caracterizar-se-ia por arenitos quartzosos, ligeiramente feldspáticos e/ou caulínicos, às vezes conglomeráticos, portadores de abundantes troncos e fragmentos de madeira silicificada.

\section{Panorama atual (2000 ao presente)}

Assine (2007) e Araújo et al. (2008) propuseram a redefinição da Formação Abaiara na qual incluíram exposições incluídas na Formação Missão Velha, tais como os afloramentos da Grota Funda, uma das mais tradicionalmente relacionadas à unidade, e do Morro do Cruzeiro. Argumentaram os autores que a presença de lenhos fósseis silicificados não definem a unidade, pois estes poderiam ser retrabalhados e se depositarem nos arenitos da Formação Abaiara. No entanto, os autores não cartografaram individualmente as unidades Missão Velha e Abaiara e nem demonstraram a nova redefinição litoestratigráfica através de datações bioestratigráficas. Ademais, posteriormente, Fambrini et al. (2011, 2013c, d, 2017) demonstraram com seções estratigráficas, estudos de fácies, paleocorrentes e de sistemas deposicionais que os troncos físseis silicificados são restritos à Formação Missão Velha. Além disso os troncos fósseis constituem-se em elementos de correlação regional e internacional (bacias do Rifte
Recôncavo-Tucano-Jatobá, Sergipe-Alagoas e Gabão, na África Ocidental).

Freitas et al. (2008) sustentaram a definição de Formação Missão Velha pautada pela presença de corpos de arenitos variados que portariam lenhos fósseis. Tal proposta foi seguida por Fambrini et al. (2009, 2011, 2017). Estes autores elaboraram análises detalhadas de fácies, paleocorrentes e sistemas deposicionais para individualizar as unidades Missão Velha e Abaiara, seguindo a proposição de Ponte \& Appi (1990), Assine (1992) e Freitas et al. (2008).

Fambrini et al. (2011) identificaram uma discordância interna na unidade, separando-a em duas sequências estratigráficas: Sequência 1 e Sequência 2. A sucessão do empilhamento da Sequência 1 refere-se a uma passagem de sistemas lacustres com contribuição fluvial, sistema fluvial meandrante com retrabalhamento eólico e depósitos de sistema fluvial entrelaçado, da base para o topo, respectivamente, e a Sequência 2 corresponde a sua porção superior e tem contato bem definido entre a sequência sotoposta por superfície com discordância erosiva, marcada pela presença de arenitos e conglomerados de sistema fluvial entrelaçado de alta energia, e mudança de sentido de paleocorrentes de S-SE para NW$\mathrm{SW}$, mudança observada também nos demais depósitos remanescentes do Andar Dom João apresentada por Kuchle et al. (2011). Contudo, em estudo mais específico sobre o início de Rifte na Bacia do Araripe, Scherer et al. (2014) demonstra que o sistema fluvial preconiza o sistema fluvial meandrante que recobre toda a formação, e que tal configuração poderia ser motivada por uma reestruturação tectônica da região, em conformidade com as propostas de Fambrini et al. (2011) e Kuchle et al. (2011). Nesta fase, a discussão acerca do topo da Formação Missão Velha tomou robustez, concluindo que se trata de uma discordância marcada por um recobrimento expansivo de depósitos deltaicos relacionados à Formação Abaiara (Scherer et al., 2014; Fambrini et al., 2017).

A Tabela 1 sumariza a evolução dos conhecimentos relativa à abrangência 
estratigrafia e delimitação dos depósitos definidores da unidade. Contudo, os limites da unidade permaneceram em desacordo acerca de sua natureza, tipo e caráter tectônico. As características tectonoestratigráficas da unidade serão discutidas a seguir.

Tabela 1 - Evolução dos conhecimentos modificadores da delimitação dos depósitos definidores da Formação Missão Velha.

\begin{tabular}{|c|c|c|c|c|c|c|}
\hline $\begin{array}{c}\text { Alemão \& } \\
\text { Alemão } \\
\text { (1862) }\end{array}$ & $\begin{array}{l}\text { Small } \\
(1913)\end{array}$ & $\begin{array}{c}\text { Beurlen } \\
(1962,1963)\end{array}$ & $\begin{array}{c}\text { Gaspary \& } \\
\text { Anjos } \\
(1964) \\
\end{array}$ & $\begin{array}{l}\text { Braun } \\
(1966)\end{array}$ & $\begin{array}{c}\text { Mabesoone } \\
\text { \& Tinoco } \\
(1973)\end{array}$ & $\begin{array}{l}\text { Moraes et al. } \\
\text { (1976) }\end{array}$ \\
\hline \multirow{2}{*}{$\begin{array}{l}\text { "Arenitos } \\
\text { portadores } \\
\text { de madeira } \\
\text { petrificada" }\end{array}$} & \multirow[t]{2}{*}{$\begin{array}{l}\text { Arenito } \\
\text { Inferior }\end{array}$} & \multirow[t]{2}{*}{$\begin{array}{l}\text { Fm. Missão } \\
\text { Velha }\end{array}$} & $\begin{array}{l}\text { Fm. } \\
\text { Missão } \\
\text { Velha }\end{array}$ & \multirow[t]{2}{*}{$\begin{array}{l}\text { Fm. } \\
\text { Sergi }\end{array}$} & Fm. Sergi & $\begin{array}{c}\text { Fácies } \\
\text { arenosa do } \\
\text { Arenito } \\
\text { Inferior }\end{array}$ \\
\hline & & & $\begin{array}{c}\text { Fm. Brejo } \\
\text { Santo }\end{array}$ & & $\begin{array}{c}\text { Fm. } \\
\text { Aliança }\end{array}$ & $\begin{array}{l}\text { Unidade } \\
\text { Inferior }\end{array}$ \\
\hline
\end{tabular}

Tabela $1-$ (cont.).

\begin{tabular}{|c|c|c|c|c|}
\hline $\begin{array}{c}\text { Ponte e } \\
\text { Appi (1990) }\end{array}$ & $\begin{array}{c}\text { Assine } \\
(1990,1992)\end{array}$ & $\begin{array}{l}\text { Assine } \\
(2007)\end{array}$ & $\begin{array}{l}\text { Araújo et al. } \\
\text { (2008) }\end{array}$ & $\begin{array}{c}\text { Fambrini et al. } \\
(2011,2017)\end{array}$ \\
\hline Fm. Abaiara & Fm. Abaiara & \multirow{2}{*}{ Fm. Abaiara } & \multirow{2}{*}{ Fm. Abaiara } & Fm. Abaiara \\
\hline \multirow{2}{*}{$\begin{array}{l}\text { Fm. Missão } \\
\text { Velha }\end{array}$} & \multirow{2}{*}{$\begin{array}{l}\text { Fm. Missão } \\
\text { Velha }\end{array}$} & & & $\begin{array}{l}\text { Fm. Missão Velha } \\
\text { (Sequência 2) }\end{array}$ \\
\hline & & $\begin{array}{l}\text { Fm. Missão } \\
\text { Velha }\end{array}$ & $\begin{array}{l}\text { Fm. Missão } \\
\text { Velha }\end{array}$ & $\begin{array}{l}\text { Fm. Missão Velha } \\
\quad \text { (Sequência 1) }\end{array}$ \\
\hline $\begin{array}{l}\text { Fm. Brejo } \\
\text { Santo }\end{array}$ & $\begin{array}{l}\text { Fm. Brejo } \\
\text { Santo }\end{array}$ & $\begin{array}{l}\text { Fm. Brejo } \\
\text { Santo }\end{array}$ & $\begin{array}{l}\text { Fm. Brejo } \\
\text { Santo }\end{array}$ & $\begin{array}{l}\text { Fm. Brejo } \\
\text { Santo }\end{array}$ \\
\hline
\end{tabular}

\section{TECTONOESTRATIGRAFIA}

Os eventos tectônicos que ocasionaram a fragmentação do Supercontinente Gondwana e a abertura do Oceano Atlântico Sul propiciaram a formação de depressões estruturais e seu preenchimento posterior durante o Mesozoico (Petri, 1987), tais como a Bacia do Araripe. De acordo com Brito Neves (1990), tais bacias acham-se dispostas nos trends NE-SW a E-W que coincidem com descontinuidades do Pré-Cambriano. Esta constatação sugere o aproveitamento destas estruturas para a instalação e desenvolvimento das bacias, ou nas palavras do autor: "o estigma de herança tectônica das estruturas do embasamento por todos os estágios evolutivos". Isto fica comprovado pela concordância das direções principais dos falhamentos da bacia com descontinuidades do embasamento (Ponte \& Ponte-Filho, 1996). A Bacia do Araripe apresenta estruturação segundo as direções NE-SW (falhas normais) a E-W (falhas transcorrentes) e, subordinadamente, NW-SE (falhas transcorrentes e normais), coincidentes com descontinuidades do embasamento Pré-Cambriano (Matos, 1992, 1999).

A evolução tectônica da Bacia do Araripe foi resumida por Ponte \& Ponte Filho (1996), que reconheceram três estágios 
tectônicos nesta bacia (pré-, sin- e pós-rifte), onde considerou-se que a sequência juroneocomiana (formações Brejo Santo e Missão Velha) foi depositada no estágio prérifte. Devido ao estiramento crustal houve a formação de uma extensa e rasa bacia interior chamada Depressão Afro-Brasileira (Ponte \& Asmus, 1976, 1978). Em seguida houve a deposição das rochas sedimentares do estágio sin-rifte (Formação Abaiara), caracterizado por acentuada subsidência e formação de horstes e grabens. Posteriormente, ocorreu a deposição da sequência aptiano-albiana compreendendo um ciclo sedimentar transgressivo/regressivo quase completo, marcado pela formação de uma superfície erosiva bem definida pela discordância préaptiana. A seguir evento de soerguimento epirogênico no Nordeste brasileiro resultou em deposição continental (albianocenomaniano?). Todas estas sequências seriam pós-rifte.

Posteriormente, as tectonossequências deposicionais foram redefinidas por Fambrini et al. (2011) em base aos trabalhos de Prosser (1993) e de Almeida et al. (2009), em que a Formação Missão Velha está compreendida pela Sequência de Início de Rifte a Clímax de Rifte Inferior (Sequência 1) juntamente com a Formação Brejo Santo, e pela Sequência de Clímax de Rifte Intermediário a Clímax de Rifte (Sequência 2) juntamente com a Formação Abaiara.

Kuchle et al. (2011), em extensa contribuição estratigráfica ao Andar Dom João, identificou nesta três sequências deposicionais distintas: (i) SEQ-1, depósitos fluviais e lacustres com superfícies de inundação bem definidas e que depositariam a Formação Brejo Santo a partir do Lago Capianga (sexta inundação); SEQ-2, depósitos fluviais entrelaçados com mudanças bruscas nas direções de paleocorrente com relação à SEQ-1; e SEQ3 , relacionada aos depósitos de folhelho de topo. Através do estudo de paleocorrentes, os autores interpretaram a mudança do comportamento aos estágios finais deposição da SEQ-1 como uma clara mudança do depocentro, centralizado numa depressão endorreica para uma depressão ampla com altos internos e vários depocentros, resultante de atividade tectônica durante a deposição do Andar Dom João.

Sob esta ótica, Kuchle et al. (2011) e mais tarde Scherer et al. (2014) em redefinição das tectonossequências na bacia do Araripe, justificam que o termo "prérifte" é usado para designar rochas que são completamente desligadas ao processo de rifteamento, consistindo de um embasamento sedimentar no qual a tafrogênese agirá (Prosser, 1993; Bosence, 1998). Normalmente os depósitos pré-rifte são dezenas a centenas de milhões de anos mais antigos que os depósitos acumulados durante o evento de rifteamento (Bosence, 1998). Baseando-se nisto, os autores utilizam a denominação Início de Rifte (Morley, 2002) para os estratos do Andar Dom João na Bacia do Araripe. Deste modo, Scherer et al. (2014) atribuíram à Formação Missão Velha duas das tectonossequências propostas (sequências II e III), no âmbito de uma análise das unidades compreendidas entre Jurássico Superior-Neocomiano.

A Sequência II (Fig. 2a) compõe grande parte da estratigrafia da Formação Missão Velha e subdivide-se em duas associações faciológicas: canais fluviais e barras de canal. A primeira associação faciológica é composta de arenitos muito grossos portando lenhos fósseis com espessuras variando entre 5,0 e $15,0 \mathrm{~m}$, com superfícies erosivas na base e contendo estratificações planares, cruzadas e de baixo ângulo com plaeofluxo geral para SE. Este primeiro pacote de sedimentos, da base, foi interpretado por Scherer et al. (2014) como um sistema de canais fluviais de baixa sinuosidade pela uniformidade dos padrões de paleocorrentes. O pacote sobreposto, interpretado como depósitos de transbordamento (overbank), que por sua vez, propiciou camadas maciças de argila vermelha com cerca de $50 \mathrm{~cm}$ de espessura, sedimentadas nos bordos dos canais, carga em suspensão que decantou em momentos de desconfinamento do leito fluvial.

A Sequência III (Fig. 2b), no entendimento de Scherer et al. (2014), corresponderia ao topo da Formação Missão 
Velha e engloba unidade de difícil distinção das duas associações faciológicas presentes pela ausência de inconformidade e superfície erosional. No entanto, o surgimento de um horizonte de conglomerado e a mudança do paleofluxo denotam variação considerável no padrão deposicional. A geometria das camadas com concavidade voltada para cima infere um sistema de canais fluviais. Contudo está presente nesses estratos uma mudança considerável no regime do paleofluxo da sedimentação, caracterizando uma mudança do depocentro da bacia e, consequentemente, uma alteração da área fonte de sedimentos. $\mathrm{O}$ padrão de paleofluxo inverte-se para direções entre SW e NW.

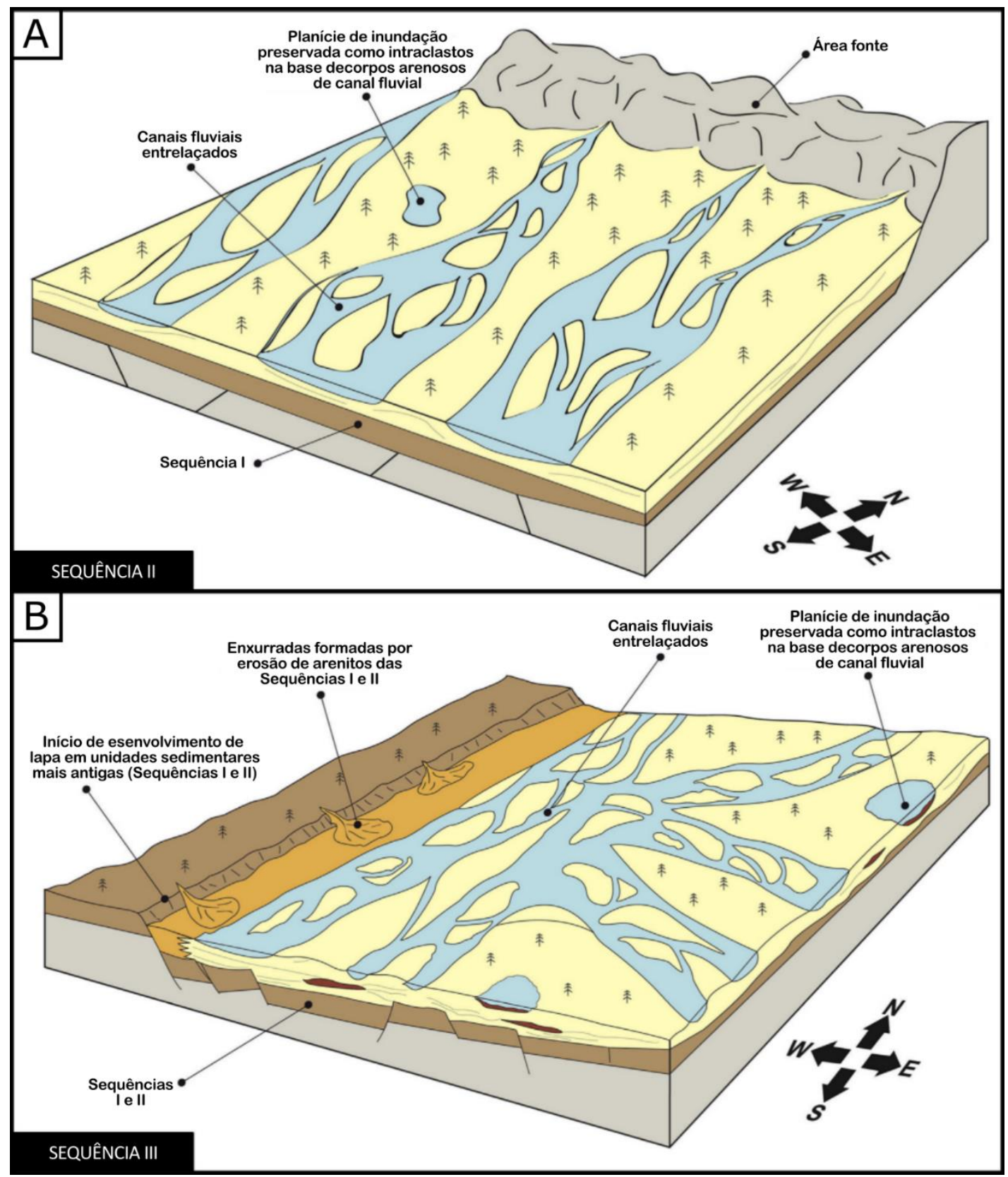

Figura 2 - Modelos deposicionais retratando a evolução temporal das sequências que compreendem a Formação Missão Velha em distintos estágios tectônicos de rifte, sendo (a) a Sequência II interpretada como um sistema de canais fluviais de baixa sinuosidade de plaeofluxo geral para SE; e (2) a Sequência III tem seu depósito de canais fluviais marcado por um contato erosivo na base com a Sequência II, e inversão do padrão de paleofluxo para direções entre SW e NW (modificado de Scherer et al., 2014). 


\section{CARACTERIZAÇÃO DA UNIDADE}

A Formação Missão Velha em seu sentido original e primário moderno (Beurlen, 1962, 1963) foi definida para agregar arenitos e conglomerados portadores de troncos fósseis silicificados. Proposições modificadoras da coluna litoestratigráfica da Bacia do Araripe somente vieram à tona no final da década de 1980 (Ghignone et al., 1986; Berthou et al., 1988) e, principalmente, no início da década de 1990 (Ponte et al., 1990; Berthou, 1990; Cavalcanti e Viana, 1992; Ponte \& Appi, 1990; Assine, 1990, 1992). Dentre estas propostas obteve destaque o trabalho de Ponte \& Appi (1990). Os autores separaram a sucessão arenítica em três unidades, mantendo a denominação tradicional Formação Missão Velha aos arenitos grossos portadores de troncos silicificados posicionando-os no Andar Dom João. Esta proposição apresentaria como importantes afloramentos uma exposição distante $2 \mathrm{~km}$ da cidade de Abaiara, conhecida como Morro do Cruzeiro, e a exposição da Grota Funda, a cerca de $7 \mathrm{~km}$ da cidade de Missão Velha.

Com base na revisão apresentada, partimos da definição de Formação Missão Velha de Ponte \& Appi (1990), seguida por Assine (1990, 1992), Neumann (1999), Neumann \& Cabrera (2000) e revisada por Arai (2006), na qual esta unidade é constituída predominantemente por corpos arenosos amalgamados, lateralmente contínuos e portadores de abundantes troncos fósseis, onde os pelitos subordinam-se (Fambrini et al. 2011). Esta foi a tônica de Fambrini et al. (2011, 2017) no qual são discutidos os elementos arquiteturais e as fácies para a elaboração dos sistemas deposicionais e do arcabouço estratigráfico de sequências da unidade.

No que tange a revisão estratigráfica aqui discutida, a litoestratigrafia é o que importa. Com ela que os geólogos se comunicam e se representa cartograficamente as unidades em mapa; e com ela as unidades recebem as denominações. É no sentido prim,ordial de Beurlen $(1962,1963)$ que reside esta definição. Isto está perfeitamente em conjunção com o Código de Nomenclatura estratigráfica Brasileiro (Comissão Especial de Nomenclatura Estratigráfica, 1986). Outras discussões a respeito de pontos de vista estratigráficos tornam-se inócuas quando se observa esta questão fundamental.

\section{Litoestratigrafia}

O contato entre as formações Brejo Santo e Missão Velha é concordante, segundo Assine (1990, 1992; Fambrini et al., $2013 b$, 2017) marcado por uma passagem gradual de fácies pelíticas avermelhadas para fácies psamíticas sobrepostas, que denotam pouca variação granulométrica na vertical, ilustrada pelo padrão em caixa observado no intervalo 837 a $1.023 \mathrm{~m}$ do poço estratigráfico 2-AR-1-CE (Assine, 1992). Em nosso estudo observou-se a transição por interdigitação entre os pelitos avermelhados da Formação Brejo Santo e os arenitos estratificados amarelados da Formação Missão Velha (Fig. 3). A Figura 4 exibe a seção estratigráfica medida relativa à Figura 3 . Por vezes esse contato entre as formações é brusco.

Os arenitos contêm estratos comumente decimétricos, com estratificações cruzadas tabulares ou acanaladas na maior parte das vezes (Assine, 1990, 1992). Por vezes, níveis descontínuos, decimétricos a métricos, de siltitos arroxeados podem ocorrer intercalados. Fambrini et al. (2011, 2017) identificaram nódulos e marcas de raízes no nível de siltito que marca o topo da Sequência I, caracterizando-o como um nível de paleossolo. O perfil estratigráfico vertical, mostrando granocrescência ascendente gradual dos pelitos avermelhados da Formação Brejo Santo para os arenitos da Formação Missão Velha, permite interpretar um empilhamento sedimentar progradante, onde lagos rasos (playa-lake) foram colmatados por sistemas fluviais efêmeros, através de rios entrelaçados de pequeno a médio porte, mas de alta energia a julgar pela composição litológica e dimensões dos estratos.

Estes sedimentos correlacionam-se, ao nível regional, com aqueles das formações 
Sergi, das bacias do Recôncavo-TucanoJatobá (Brito, 1987; Ponte, 1991; Assine, 1992, Valença et al., 2003; Arai, 2006; Scherer et al., 2007), e Serraria, da Bacia de
Sergipe-Alagoas (Branner, 1890; Assine 1992; Da Rosa e Garcia, 2000; Arai, 2006; Fambrini et al., 2017).
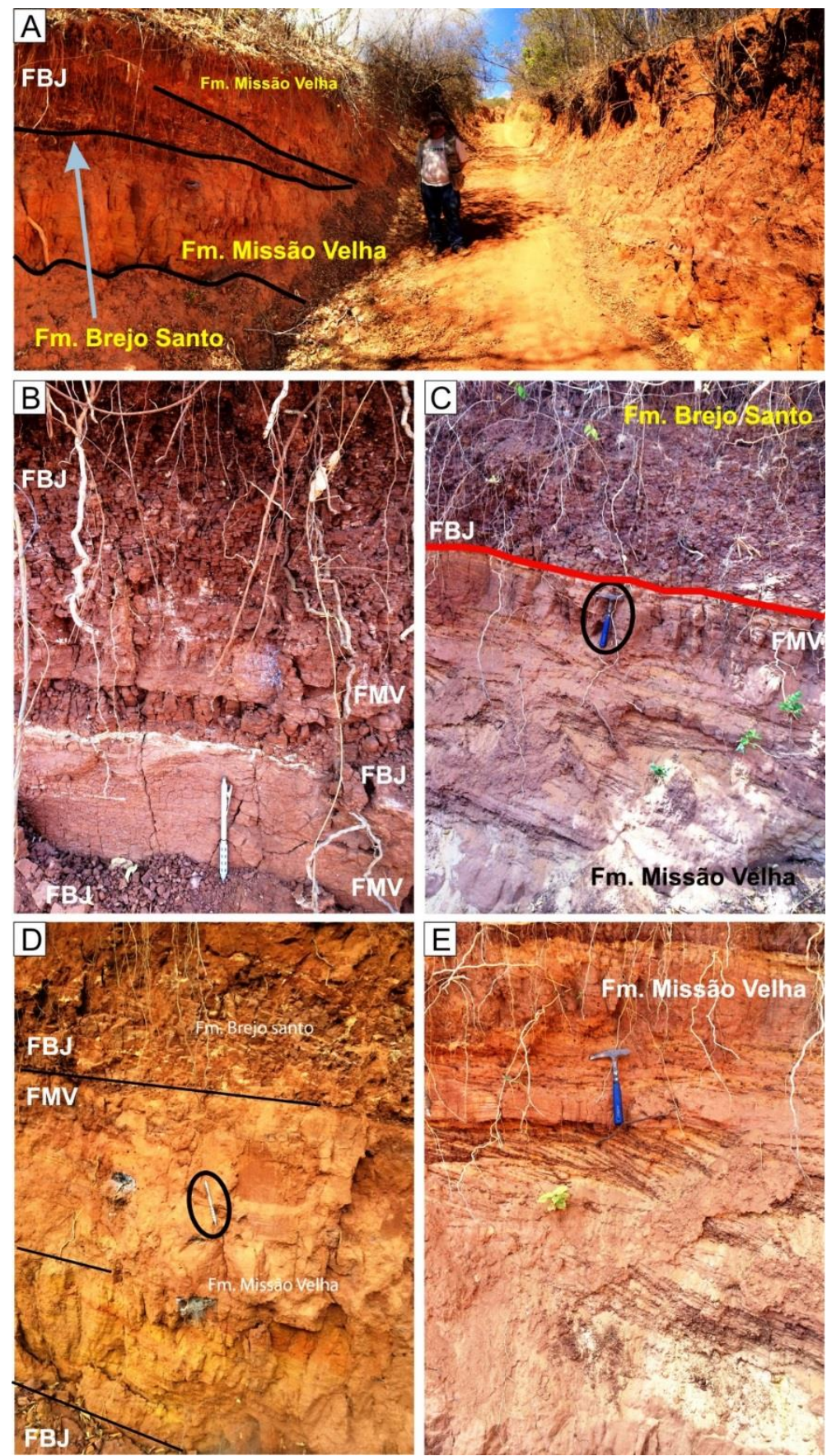

Figura 3 - Contato geológico entre as formações Brejo Santo (BJ - argilitos e folhelhos avermelhados) e Missão Velha (MV - arenitos médios a finos estratificados) em Milagres - CE (491422/9197252 - Datum UTM SIRGAS2000/24S). (a) Visão geral do afloramento estudado com o contato das formações BJ e MV; (b, c, d) interdigitação entre corpos de argilitos e folhelhos lacustres e arenitos estratificados; (e) arenitos médios a finos com estratificações cruzadas tabulares e delgadas camadas de argilitos interpretados como porções dos pelitos lacustres em meio ao sistema fluvial efêmero. 

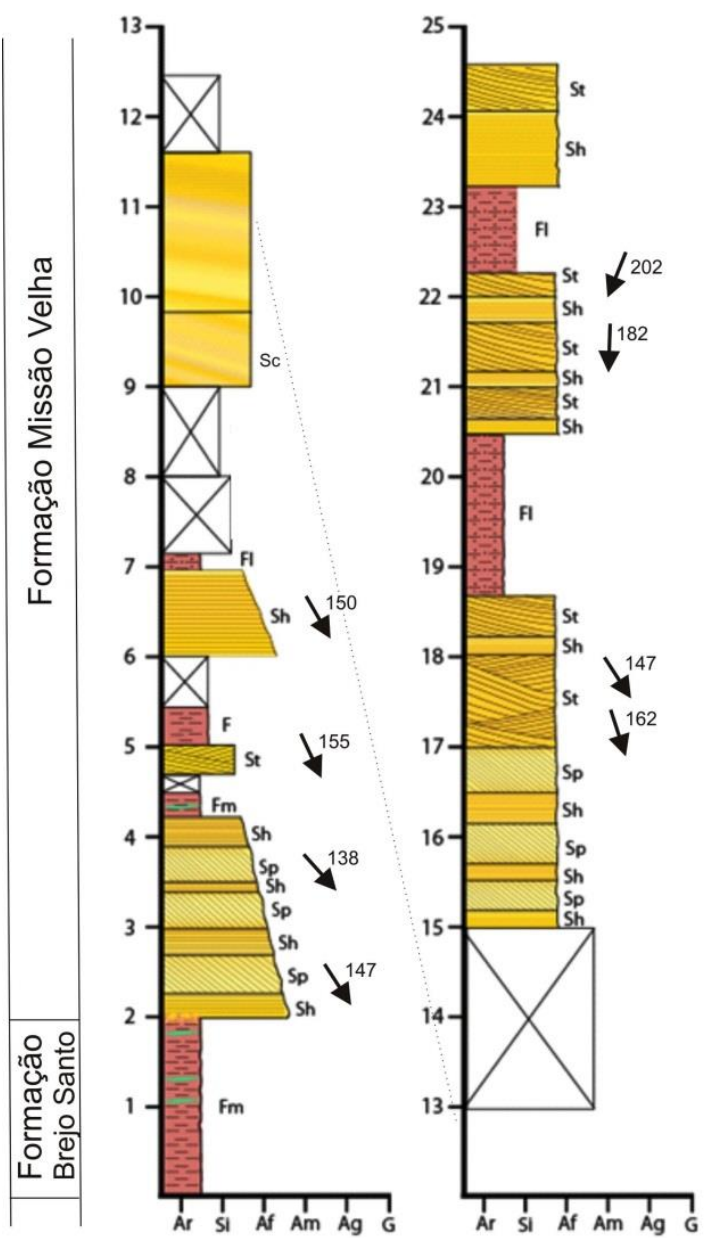

\section{Litofácies}

Sc- arenitos com laminação cruzada cavalgante (climbing-ripples)

Sh- arenitos com estratificação plano-paralela

Sp- arenitos com estratificação cruzada tabular

St- arenitos com estratificação cruzada acanalada

Scg- arenitos com seixos e conglomeráticos

Cm- conglomerados maciços de seixos a calhaus

Sca- calcários argilosos e arenitos calcíferos

Fm- argilitos maciços avermelhados

Fl- argilitos laminados

\section{Principais feições sedimentarres}

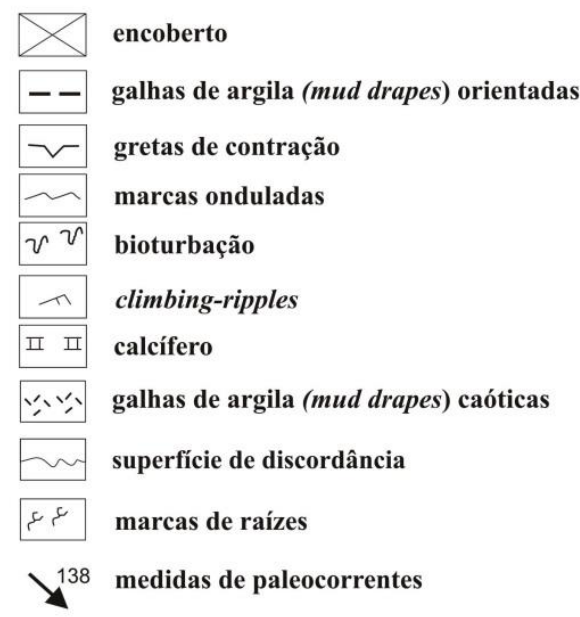

Figura 4 - Seção estratigráfica do contato inferior da Formação Missão Velha com a Formação Brejo Santo com presença de interdigitação entre corpos de folhelhos e argilitos da Formação Brejo Santo e de arenitos estratificados da Formação Missão Velha. Notar a passagem gradual por intercalação entre a unidades. A figura também exibe a intercalação entre corpos de folhelhos e arenitos interpretados como pequenas planícies de inundação no meio do sistema fluvial entrelaçado da Formação Missão Velha (modificado de Fambrini et al., 2017).

\section{Fácies e arquitetura deposicional}

Fambrini et al. (2011) elaboraram análises de fácies, paleocorrentes e sistemas deposicionais para individualizar as unidades Missão Velha e Abaiara, seguindo as proposições de Ponte \& Appi (1990), Assine (1992) e Freitas et al. (2008). Tentativamente os autores individualizaram ambas unidades em mapa com base em critérios estratigráficos, paleontológicos, de paleocorrentes e de sistemas deposicionais. Pela primeira vez proporcionou-se a compreensão da distribuição e da evolução das rochas sedimentares da Formação Missão Velha, através do detalhamento dos conjuntos previamente identificados, o reconhecimento de alguns sistemas deposicionais de menor abrangência anteriormente não observados e uma correlação mais clara das transições laterais dos sistemas deposicionais (Tabela 2). 
Tabela 2 - Resumo das principais fácies da Formação Missão Velha na região homônima, Bacia do Araripe. Esquema de fácies a partir de Miall (1978, 1996), siglas entre parêntesis em inglês. (Fonte: Fambrini et al., 2011)

\begin{tabular}{|c|c|c|}
\hline $\begin{array}{l}\text { CÓDIG } \\
\text { O }\end{array}$ & LITOFÁCIES & INTERPRETAÇÃO \\
\hline $\mathrm{Ce}(\mathrm{Gs})$ & $\begin{array}{l}\text { Conglomerados com estratificação } \\
\text { plano-paralela }\end{array}$ & $\begin{array}{c}\text { Depósitos de correntes aquosas em barras } \\
\text { longitudinais fluviais. }\end{array}$ \\
\hline Acg & $\begin{array}{c}\text { Arenitos conglomeráticos com } \\
\text { estratificações cruzadas acanaladas }\end{array}$ & $\begin{array}{l}\text { Depósitos de dunas subaquáticas de } \\
\text { regime de fluxo inferior em canais fluviais } \\
\text { entrelaçados. }\end{array}$ \\
\hline Aa $(\mathbf{S t})$ & $\begin{array}{l}\text { Arenitos grossos a médios com } \\
\text { estratificações cruzadas acanaladas }\end{array}$ & $\begin{array}{c}\text { Migração de formas de leito 3D, } \\
\text { Depósitos de dunas subaquáticas de } \\
\text { cristas sinuosas em regime de fluxo } \\
\text { inferior em canais fluviais entrelaçados de } \\
\text { alta energia. }\end{array}$ \\
\hline At (Sp) & $\begin{array}{l}\text { Arenitos grossos a médios com } \\
\text { estratificações cruzadas tabulares }\end{array}$ & $\begin{array}{c}\text { Depósitos de barras longitudinais de } \\
\text { correntes fluviais de rios entrelaçados, } \\
\text { associados com arenitos da fácies Aa ou } \\
\text { de ocorrência isolada. }\end{array}$ \\
\hline Ap (Sh) & $\begin{array}{l}\text { Arenitos grossos a médios com } \\
\text { estratificação plano-paralela }\end{array}$ & $\begin{array}{l}\text { Depósitos de fluxo laminar superior, } \\
\text { associado a diversos processos conforme a } \\
\text { associação de fácies em que se encontram. }\end{array}$ \\
\hline $\operatorname{Ac}(\mathrm{Sr})$ & $\begin{array}{c}\text { Horizontes heterolíticos, arenitos finos } \\
\text { com laminações cruzadas cavalgantes e } \\
\text { pelitos laminados }\end{array}$ & $\begin{array}{c}\text { Canais de crevasse gerados por canais } \\
\text { secundários formados pelo rompimento de } \\
\text { diques marginais. }\end{array}$ \\
\hline $\operatorname{Ad}(\mathbf{S d})$ & $\begin{array}{l}\text { Arenitos finos com estruturas de } \\
\text { deformação }\end{array}$ & $\begin{array}{l}\text { Ação de correntes subaquosas densas que } \\
\text { provocaram deformação nas camadas não } \\
\text { consolidadas de substrato fluvial. }\end{array}$ \\
\hline Ar & $\begin{array}{c}\text { Arenitos finos a médios com } \\
\text { estratificações cruzadas truncantes }\end{array}$ & $\begin{array}{l}\text { Depósitos de lençóis eólicos devido ao } \\
\text { retrabalhamento de sedimentos fluviais. }\end{array}$ \\
\hline Sl (Fl) & Siltitos e arenitos finos laminados & $\begin{array}{c}\text { Depósitos de correntes subaquáticas } \\
\text { predominantemente de regime de fluxo } \\
\text { inferior. }\end{array}$ \\
\hline Fl (Fh) & Argilitos laminados & $\begin{array}{l}\text { Depósitos distais de planície de inundação } \\
\text { sob ação de correntes subaquáticas } \\
\text { predominantemente em regime de fluxo } \\
\text { inferior. }\end{array}$ \\
\hline $\begin{array}{l}\text { Fsm } \\
(\text { Fm) }\end{array}$ & Argilitos maciços & $\begin{array}{l}\text { Depósitos distais de planície de inundação } \\
\text { sob ação de suspensão. }\end{array}$ \\
\hline $\mathbf{P}(\mathbf{C})$ & Pedogenética & $\begin{array}{c}\text { Presença de nível de exposição subaérea e } \\
\text { pausa na sedimentação. }\end{array}$ \\
\hline
\end{tabular}

A associação de fácies de Arenitos Estratificados e Amalgamados (fácies Ce, Aa, At, Ap e Ad) indicam deposição em canais (elemento $\mathrm{CH}$ ), lençóis de areia laminados (LS), barras cascalhosas (GB) e acreção a favor do fluxo em depósitos de canais fluviais entrelaçados, multiepisódicos, com sedimentação em lâmina d’água variável. A associação de fácies de Arenitos Tabulares Sobrepostos envolve o elemento arquitetural Lençóis de Areia Laminada (LS) denota depósitos desconfinados formados por fluxo superior por meio de inundações rápidas em planície aluvial arenosa A associação de fácies de Arenitos em Lençóis Amalgamados (fácies Ce, Aa, At, Ap e Ar) 
sugere deposição em lençóis de areia laminados e formas de leitos arenosos (SB) em sistema fluvial entrelaçados de baixo confinamento, canais instáveis e raros depósitos de planície de inundação. Os depósitos finos de transbordamento (elemento FF com as Fácies Fsm e Fl) representam depósitos de planície de inundação ocorrentes em planície aluvial, com áreas alagadas e lagos temporários, provavelmente sistema fluvial meandrante (Tabela 3). Assim, as fácies e associações de fácies descritas foram interpretadas como geradas por sistemas aluviais representados por (i) sistemas fluviais entrelaçados de alta energia com as seguintes características: ciclos granodecrescentes, estratificações cruzadas acanaladas, truncamentos entre estratos cruzados, feições de corte e preenchimento (cut-and-fill), presença de corpos de arenitos de geometria lenticular, feições canalizadas, seixos esparsos e retrabalhamento eólico (Fácies Ar) e (ii) sistemas fluviais meandrantes pela presença de depósitos de planície de inundação (folhelhos), de crevasse splays e de barras em pontal que os caracterizariam.

Tabela 3 - Associações de fácies e respectivos elementos arquiteturais da Formação Missão Velha na região homônima, Bacia do Araripe. (Fonte: Fambrini et al., 2011)

\begin{tabular}{|c|c|c|c|}
\hline $\begin{array}{l}\text { ASSOCIAÇÃO } \\
\text { DE FÁCIES }\end{array}$ & $\begin{array}{l}\text { ASSEMBLEIA DE } \\
\text { LITOFÁCIES }\end{array}$ & $\begin{array}{c}\text { ELEMENTOS } \\
\text { ARQUITETURAIS }\end{array}$ & INTERPRETAÇÃO \\
\hline $\begin{array}{c}\text { Arenitos e } \\
\text { Conglomerados } \\
\text { Estratificados e } \\
\text { Amalgamados }\end{array}$ & $\begin{array}{c}\mathrm{Cm}, \mathrm{Ce}, \mathrm{Acg}, \\
\mathrm{Aa}, \mathrm{Ap}, \mathrm{At}, \mathrm{e} \mathrm{Ad}\end{array}$ & $\begin{array}{l}\text { Canais, Lençóis de } \\
\text { Areia Laminados, } \\
\text { Barras Cascalhosas }\end{array}$ & $\begin{array}{c}\text { Depósitos de Canais fluviais } \\
\text { entrelaçados, episódicos, } \\
\text { deposição com lâmina d'água } \\
\text { variável }\end{array}$ \\
\hline $\begin{array}{l}\text { Arenitos em } \\
\text { Lençóis } \\
\text { Amalgamados }\end{array}$ & $\begin{array}{c}\mathrm{Ce}, \mathrm{Acg}, \mathrm{Aa}, \mathrm{Ap}, \mathrm{At}, \\
\text { e Ac }\end{array}$ & $\begin{array}{l}\text { Barras e Formas de } \\
\text { Leito Arenosas e } \\
\text { Lençóis de Areia } \\
\text { Laminados }\end{array}$ & $\begin{array}{c}\text { Depósitos de sistema fluvial } \\
\text { entrelaçado de baixo } \\
\text { confinamento, canais instáveis } \\
\text { pouco definidos e raros } \\
\text { depósitos de planície de } \\
\text { inundação }\end{array}$ \\
\hline $\begin{array}{c}\text { Arenitos } \\
\text { Tabulares } \\
\text { Sobrepostos }\end{array}$ & $\begin{array}{c}\text { Acg, Ap, At, Ac e } \\
\text { Fl }\end{array}$ & $\begin{array}{c}\text { Lençóis de Areia } \\
\text { Laminada }\end{array}$ & $\begin{array}{l}\text { Depósitos desconfinados } \\
\text { formados por fluxo superior } \\
\text { por meio de inundações } \\
\text { rápidas em planície aluvial } \\
\text { arenosa }\end{array}$ \\
\hline $\begin{array}{l}\text { Lentes de } \\
\text { Arenitos } \\
\text { Sobrepostos }\end{array}$ & $\begin{array}{c}\text { Acg, Aa, At, Ap e } \\
\text { Ac }\end{array}$ & Canais de crevasses & $\begin{array}{l}\text { Canais de } \text { crevasses gerados } \\
\text { por canais secundários } \\
\text { formados pelo rompimento de } \\
\text { diques marginais }\end{array}$ \\
\hline $\begin{array}{l}\text { Intercalações de } \\
\text { Pelitos e } \\
\text { Arenitos Finos } \\
\text { Tabulares } \\
\end{array}$ & Ac, Sl, Fl, Fm & $\begin{array}{c}\text { Finos de } \\
\text { Transbordamento }\end{array}$ & $\begin{array}{l}\text { Depósitos de finos gerados por } \\
\text { processos de suspensão em } \\
\text { lagos temporários ou perenes } \\
\text { em planície de inundação }\end{array}$ \\
\hline $\begin{array}{l}\text { Sedimentos } \\
\text { Finos de Planície } \\
\text { de Inundação } \\
\end{array}$ & $\mathrm{Fl}, \mathrm{Fm}$ & $\begin{array}{c}\text { Finos de } \\
\text { Transbordamento }\end{array}$ & $\begin{array}{c}\text { Depósitos de finos originados } \\
\text { por processos de suspensão } \\
\text { em planície aluvial }\end{array}$ \\
\hline $\begin{array}{l}\text { Arenitos em } \\
\text { Lençol }\end{array}$ & $\mathrm{Ar}$ & - & $\begin{array}{l}\text { Depósitos de lençóis de areia } \\
\text { eólicos devido ao } \\
\text { retrabalhamento de } \\
\text { sedimentos fluviais arenosos }\end{array}$ \\
\hline
\end{tabular}


Conteúdo fossilífero

\section{PALINOLOGIA}

Viana (1980) relata que o sedimento pertencente ao Andar Dom João compreende as camadas fossilíferas mais antigas da sequência continental mesozoica, de idade neojurássica. São representados por uma associação de ostracodes lacustrinos onde Bisulcocypris e Metacypris são predominantes, onde os dois espécimes mostram dimensões reduzidas fora do normal. Lado a lado com $B$. Pricei, o principal fóssil guia, são encontrados Darwinula cf.; D. Oblonga (Roemer), razoavelmente frequente e de dimensões normais; conchostráceos e restos de peixes são também encontrados e, na porção superior da sequência, onde microfósseis são praticamente inexistentes, são encontrados troncos silicificados de coníferas em certas regiões, dentro de uma espessa camada arenosa.

Análises palinológicas realizadas na Formação Missão Velha apresentam associação com presença de pólen em díades lisas e não estriadas (Dicheiropollis sp. A), presença de Vitreisporites pallidus, frequência relativamente alta (30\%) de esporos triletes com participação apreciável (5\%) dos verrucados (Leptolepidites e Verrucosisporites), frequência relativamente alta $(7 \%)$ de esporos do tipo Cicatricosisporites, frequência relativamente baixa (20\%) de grãos de pólen de Classopollis, e frequência baixíssima (1\%) de grãos de pólen efedróides (Equisetosporites e Gnetaceaepollenites), apresentando-se semelhante à associação palinológica jurássica de Cuba, portanto tornando-se bastante sugestiva para esta idade (Arai et al., 2001; Coimbra et al., 2002; Arai, 2006).

A presença da palinozona Dicheiropolis (espécie Dicheiropolis sp.) na Formação Missão Velha indica idade posicionada no Andar Dom João (NRT-001) (Arai et al., 1989; Coimbra et al., 2002).

INTERPRETAÇÃO PALEOCLIMÁTICA
A abundância de largos troncos fósseis na Formação Missão Velha, significando a presença de florestas nas áreas fontes levou à interpretação clássica da predominância de climas mais úmidos no ambiente deposicional da unidade (e.g. Braun, 1966; Ponte, 1991; Fambrini et al., 2011). Fambrini et al. (2011) destacaram a ausência aparente de troncos silicificados assim como caráter efêmero dos sistemas fluviais na Sequência I, e abundância de troncos juntamente a um caráter perene do sistema fluvial (presença de macroformas) na Sequência II, levando os autores a sugerirem que entre as sequências há um considerável aumento nas condições de umidade. Esta interpretação é coerente, considerando-se que a unidade não apresenta indicadores climáticos mais óbvios de origem química ou bioquímica.

Paralelamente, Pires \& GuerraSommer (2011) através do estudo de anéis de crescimento nos troncos silicificados, apresentariam conclusões mais detalhadas acerca destes padrões paleoclimáticos. As autoras sugerem um ambiente de crescimento irregular com eventos climáticos extremos, porém, com boas condições para o desenvolvimento das árvores, com grande variabilidade anual de suprimento de água, assemelhando-se ao clima de monções segundo a classificação de Köppen (1936), onde a sazonalidade da circulação de monções resulta em invernos frios e secos e verões quentes e úmidos nas regiões continentais.

Costa et al. (2014), em estudo de condições diagenéticas, observaram que nos depósitos da Formação Missão Velha destaca-se a infiltração mecânica de argilas, que sugerem enxurradas episódicas e em profundidades rasas sob climas semiáridos. Contudo, este fenômeno não se distingue em comportamento nas seções inferior e superior da unidade.

\section{TRONCOS SILICIFICADOS}

A presença dos troncos fósseis na Formação Missão Velha foi escassamente 
relatada na literatura durante o Séc. XX, vindo a tomar papel de algum destaque apenas com a concepção do Geopark Araripe, reconhecido em 2006 pela Organização das Nações Unidas para Ciência e Cultura (UNESCO) originando, dentre os nove geossítios existentes, o Geossítio Floresta Petrificada do Cariri, notório pela abundância dos troncos silicificados no substrato e por ser seção-tipo da Formação Missão Velha (Ponte \& Appi, 1990; Freitas et al., 2008; Fambrini et al., 2009, 2010b, c; Silveira et al., 2012; Fambrini et al., 2013c, d, 2017). Contudo, entre as primeiras explorações de Beurlen $(1962,1963)$ e o advento do Geopark Araripe em 2006, a unidade sofreu degradação e numerosos saques (Silva Filho et al., 2015), sendo atualmente de difícil visualização os troncos silicificados in situ que inicialmente caracterizaram a unidade.

Os troncos fósseis da Formação Missão Velha foram tentativamente atribuídos aos gêneros Araucarioxylon (Beurlen, 1962, 1963; Carvalho et al., 2012) e Dadoxylon (Brito, 1987; Ponte et al., 1990; Freitas et al., 2008). No entanto, a atribuição original dos troncos silicificados pertencentes ao Andar Dom João ao táxon Dadoxylon benderi (Mussa, 1959) foi realizada através de uma amostra da Bacia Sergipe-Alagoas, atribuída à Formação Japoatã (Brito \& Campos, 1983), denominação estendida por conveniência nas décadas seguintes aos demais depósitos do Andar Dom João.

Contudo, Kurzawe e Merlotti (2009), em extensa revisão do gênero Dadoxylon, concluem que este é considerado ilegítimo de acordo com o Art. 52.1 do Código Internacional de Nomenclatura Botânica (McNeil et al., 2006), reiterando assim o desuso deste táxon propostos por Philippe (1993) e Bamford \& Philippe (2001).

\section{VERTEBRADOS}

A associação de paleofaunas vertebradas com a Formação Missão Velha (e.g. Brito et al., 1994; Cupello et al., 2012; Cupello et al., 2016) deve ser feita com cautela. Considerando as observações de Maisey (2000) e Toledo \& Bertini (2005), é possível constatar que este tipo de associação pode apresentar dados de afloramentos correspondentes à atual Formação Brejo Santo (sensu Ponte \& Appi, 1990), associação esta que é compreensível para trabalhos mais antigos, visto que a formalização moderna da Bacia do Araripe ainda tomava forma e alguns autores ainda utilizavam de terminologias mais antigas nas quais a Formação Brejo Santo ainda não havia sido separada da Formação Missão Velha. Contudo, se não houver rigor acerca das considerações mais atualizadas das proposições que delimitam a unidade, esta associação deve ser desencorajada.

\section{CONSIDERAÇÕES FINAIS}

Conforme a proposição deste trabalho, o registro sedimentar da Formação Missão Velha compreende os depósitos fluviais entrelaçados presentes na Bacia do Araripe e aflorantes na região do Vale do Cariri (sudeste do Estado do Ceará), composta por depósitos arenosos de grande continuidade lateral, amalgamados, por vezes interdigitados com folhelhos, com presença de troncos silicificados nas proximidades dos afloramentos das fácies conglomeráticas, sendo raras ocorrências in situ devido à degradação das exposições mais conhecidas.

A Formação Missão Velha tem como base o contato concordante e gradual lato sensu das fácies pelíticas da Formação Brejo Santo para fácies psamíticas que caracterizam a unidade, podendo ser localmente brusco; e como topo uma discordância marcada pelo recobrimento expansivo de depósitos fluvio-deltaicos relacionados à Formação Abaiara.

Os recentes avanços nos âmbitos faciológico e tectonoestratigráfico da Formação Missão Velha, demonstram que a unidade apresenta uma discordância interna e que suas sequências inferior e superior - I e II respectivamente (sensu Fambrini et al., 2011) - apresentam distinção de sentido de paleocorrentes que mudam de prioritariamente SE para NW; associação de 
fácies que mudam de depósitos fluviais com planícies de inundação intercaladas para depósitos de fundo de canal de alta energia com presença de troncos silicificados.

A ausência aparente de indicadores climáticos de origem química e bioquímica (e.g. carvão, evaporitos, bauxita, laterita, etc.) na Formação Missão Velha é um dificultador com relação a uma interpretação paleoclimática detalhada acerca da unidade, contudo, o registro de uma camada de paleossolo abre caminho para futuros trabalhos acerca de sua paleoedologia.

Embora os troncos silicificados da Formação Missão Velha sejam relatados desde a década de 1850 , a sua atribuição ao táxon Dadoxylon-Araucarioxylon é referente a uma amostra da Bacia Sergipe-Alagoas e estendida à Bacia do Araripe ao longo das décadas por conveniência. Neste contexto, conclui-se que os troncos ainda carecem de estudos paleontológicos, salientando-se a necessidade de utilização de designações genéricas válidas e legítimas na identificação taxonômica dos troncos independentemente da composição estrutural.

Ao associar paleofaunas vertebradas à Formação Missão Velha, deve atentar à precaução de estar de acordo com as proposições mais atualizadas que delimitam a unidade, a fim de não se referir equivocadamente à Formação Brejo Santo.

\section{AGRADECIMENTOS}

Este trabalho foi elaborado com auxílio financeiro do $\mathrm{CNPq}$ (Processo 476232/2006-6 concedido em nome de Gelson Luís Fambrini) a quem agradecemos o apoio e também as bolsas concedidas (bolsa de produtividade em pesquisa de V.H.M.L. Neumann e bolsa de Mestrado de Diego C. Silvestre). Ao colega e amigo fraterno Prof. Dr. Alexandre Magno Feitosa Sales (in memoriam URCA-CE) pelo auxilio nos trabalhos de campo. Ao LAGESE/DGEO/UFPE pelo apoio logístico e material. Agradecimentos são devidos também ao PPGEO - UFPE e ao Departamento de Geologia (CTG-UFPE). Os autores expressam os agradecimentos ao editor Prof. Dr. Gorki Mariano e ao revisor Prof. Dr. Mário Lima Filho pela revisão exímia e rigorosa no manuscrito submetido.

\section{REFERÊNCIAS}

ACSN (American Commission on Stratigraphic Nomenclature). 1961. Code of Stratigraphic Nomenclature. AAPG Bulletin, 45(5): 645-665.

Alemão, F.F., Alemão, M.F. 1862. Trabalhos da Commissão scientifica de exploração. Rio de Janeiro, Typographia Universal de Laemmert, 170p.

Almeida, R.P., Janikian, L., Fragoso-Cesar, A.R.S., Marconato, A. 2009. Evolution of a rift basin dominated by subaerial deposits: The Guaritas Rift, Early Cambrian, Southern Brazil. Sedimentary Geology, 217: 30-51. https://doi.org/10.1016/j.sedgeo.2009. 01.010

Arai, M. 2006. Revisão estratigráfica do Cretáceo Inferior das bacias interiores do Nordeste do Brasil. Geociências, 25(1): 7-15.

Arai, M., Hashimoto, A.T., Uesugui, N. 1989. Significado cronoestratigráfico da associação microflorística do Cretáceo Inferior do Brasil. Boletim de Geociências da Petrobrás, 3(1-2): 87103.

Arai, M.; Coimbra, J.C.; Telles Jr., A.S. 2001. Síntese Bioestratigráfica da Bacia do Araripe (Nordeste do Brasil). In: Barros, L.M.; Nuvens, P.C.; Filgueira, J.B.M. (Org.) Coleção Chapada do Araripe n. 1. Crato, pp. 109-124.

Araújo, B.C.; Morales, N.; Assine, M.L; Pellegrini, B.S. 2008. Formação Abaiara da Bacia do Araripe: importante registro da fase rifte no interior do Nordeste do Brasil. In: Congresso Brasileiro de Geologia, 44. Curitiba, 2008. Anais... Curitiba, SBG, p. 120.

Assine, M.L. 1990. Sedimentação e Tectônica da Bacia do Araripe, Nordeste do Brasil. Dissertação 
(Mestrado em Geologia Regional) Instituto de Geociências e Ciências Exatas, Universidade Estadual Paulista, Rio Claro, 124 p.

Assine, M.L. 1992. Análise estratigráfica da Bacia do Araripe, Nordeste do Brasil. Revista Brasileira de Geociências, 22(3): 289-300.

Assine, M.L. 2007. Bacia do Araripe. Boletim de Geociências da Petrobrás, 15(2): 371-389.

Assine, M.L.; Perinotto, J.A.J.; Custódio, M.A.; Neumann, V.H.M.L.; Varejao, F.G.; Mescolotti, P.C. 2014. Sequências deposicionais do Andar Alagoas da Bacia do Araripe, Nordeste do Brasil Boletim de Geociências da Petrobras, 22 (1): 3-28.

Bamford, M.K., Philippe, M. 2001. Jurassic-Early Cretaceous Gondwana homoxylous woods: a nomenclatural revision of the genera with taxonomic notes. Review of Palaeobotany and Palynology, 113: 287-297. https://doi.org/10.1016/S00346667(00)00065-8

Berthou, P. 1990. Le bassin d'Araripe et les petits bassins intracontinentaux voisins (N.E. du Brésil): formation et evolution dans le cadre de l'ouverture de 1'Atlantique Equatorial. Comparasion avec les bassins ouest-Africains situés dans le même context. In: Simpósio Sobre a Bacia do Araripe e Bacias Interiores do Nordeste, 1. Crato, 1990. Atas(...), Crato, DNPM/SBP/SBG, p. 113-134.

Berthou, P.Y., Depehces, K., Campos, D.A., Herein, J.P., Pierres, C. 1988. New data on sedimentation, paleoenvironment and stratigraphy of the Chapada do Araripe. Revista Brasileira de Geociências, 18(3): 315.

Beurlen, K. 1962. A geologia da Chapada do Araripe. Anais da Academia Brasileira de Ciências, 34(3): 365-370.

Beurlen, K. 1963. Geologia e estratigrafia da Chapada do Araripe. In: Congresso Brasileiro de Geologia, 17. Recife, 1963. Anais(...), Recife, SBG/SUDENE. 47 p. (Suplemento).
Bosence, D.W.J. 1998. Stratigraphic and sedimentological models of rift basins. In: Purser, B.H., Bosence, D.W.J. (Org.), Sedimentation and Tectonics of Rift Basins: Red Sea e Gulf of Aden. 1 ed. Londres, Chapman \& Hall, p. 9-25.

Branner, J.C. 1890. The Cretaceous and Tertiary Geology of the SergipeAlagoas Basin of Brazil. Transactions of the American Philosophical Society, $1(1)$ : 369-434. https://doi.org/10.2307/1005398

Braun, O.P.G. 1966. Estratigrafia dos Sedimentos da Parte Inferior da Região Nordeste do Brasil (Bacias do TucanoJatobá, Mirandiba e Araripe). Rio de Janeiro, DNPM/DGM. 75 p.

Brito, L.M. 1987. As unidades litoestratigráficas da passagem Jurássico-Cretáceo do Nordeste do Brasil. Revista Brasileira de Geociências, 17(2):81-85.

Brito, L.M., Campos, D.A. 1983. The Brazilian Cretaceous. Zitteliana, 10: 277-283.

Brito, P.M., Bertini, R.J., Martill, D.M., Salles, L.J. 1994. Vertebrate fauna from the Missão Velha Formation (Lower Cretaceous, N.E. Brazil). In: Simpósio Sobre as Bacias Cretácicas Brasileiras, 3. Rio Claro, 1994. Boletim de Resumos, Rio Claro, UNESP, p. 139-140.

Brito Neves, B.B. 1990. A Bacia do Araripe no contexto geotectônico regional. In: Simpósio Sobre a Bacia do Araripe e Bacias Interiores do Nordeste, 1. Crato, 1990. Atas(...), Crato, DNPM/SBP/SBG, p. 21-33.

Brito-Neves, B.B.; Santos, E.J.; Fuck, R.A.; Santos, L.C.M.L. 2016. A preserved early Ediacaran magmatic arc at the northernmost portion of the Transversal Zone central subprovince of the Borborema Province, Northeastern South America. Brazilian Journal of Geology,v. 46, n. 4, p. 491508. https://doi.org/10.1590/23174889201620160004

Brito Neves, B.B.; Santos, E. J.; Van Schmus, W.R. 2000. Tectonic history 
of the Borborema Province. In: Cordani U. G. et al. Tectonic evolution of the South America. Rio de Janeiro: $31^{\text {st }}$ International Geological Congress, 2000. p.151-182.

Carvalho, I, S., Freitas, F.I., Neumann, V.H.M.L. 2012. Chapada Do Araripe. In: Hasui, Y., Carneiro, C.R., Almeida, F. F. M., Bartorelli, A. (Org.), Geologia do Brasil. 1 ed. São Paulo, Editora Beca. p. 520-543.

Cavalcanti, V.M.M., Viana, M.S.S. 1992. Revisão estratigráfica da Formação Missão Velha, Bacia do Araripe, Nordeste do Brasil. Anais da Academia Brasileira de Ciências, 64 (2): 155-168. Chagas, D.B. 2006. Litoestratigrafia da Bacia do Araripe: Reavaliação e Propostas para Revisão. Dissertação (Mestrado em Geologia Regional) Instituto de Geociências e Ciências Exatas, Universidade Estadual Paulista, Rio Claro, 127 p.

Coimbra, J.C., Arai, M., Carreño, A.L. 2002. Lower Cretaceous microfossils from Araripe basin, Northeastern Brazil: an stratigraphical approach. Geobios, 35(6): 687-698. https://doi.org/10.1016/S00166995(02)00082-7

Comissão Especial de Nomenclatura Estratigráfica. 1986. Código Brasileiro de Nomenclatura Estratigráfica - Guia de Nomenclatura Estratigráfica. Revista Brasileira de Geociências, 16: 370-415.

Costa, A.B.S., Córdoba, V.C., Jardim De Sá, E.F., Scherer, C.M.S. 2014. Diagênese dos arenitos da Tectonossequência Rifte na Bacia do Araripe, NE do Brasil. Brazilian Journal Of Geology, 44(3): 457-470. https://doi.org/10.5327/Z23174889201400030008

Cupello, C.D., Bermúdez-Rochas, D.D., Martill, D.M., Brito, P.M. 2012. The Hybodontiformes (Chondrichthyes: Elasmobranchii) from the Missão Velha Formation (?Lower Cretaceous) of the Araripe Basin, North-East Brazil. Compter Rendus Palevol, 11(1):
41-47.

https://doi.org/10.1016/j.crpv.2011.09. 005

Cupello, C.D., Batista, T.A., Fragoso, L.G., Brito, P.M. 2016. Mawsoniid remains (Sarcopterygii: Actinistia) from the lacustrine Missão Velha Formation (Lower Cretaceous) of the Araripe Basin, North-East Brazil. Cretaceous Research, 65: 10-16. https://doi.org/10.1016/j.cretres.2016.0 4.009

Da Rosa, A.A.S., Garcia, A.J.V. 2000. Palaeobiogeographic aspects of northeast Brazilian basins during the Berriasian before the break up of Gondwana. Cretaceous Research, 21: 221-239.

https://doi.org/10.1006/cres.2000.0209

Derby, O.A. 1879. Contribuições para o estudo da geologia do valle do São Francisco. Archivo do Museu Nacional, 4: 87-119.

Fambrini, G.L., Neumann, V.H.M.L., Silva Filho, W.F., Valença, L.M.M., Lima Filho, M.F., Barbosa, J.A., Tesser Junior, S., Souza, B.Y.C. 2007. Sistemas lacustres da Bacia do Araripe, Nordeste do Brasil: resposta à subsidência e tectônica de bacias rifte. In Simpósio de Geologia do Nordeste, 22, Atas(...), pp. 101, Natal, RN.

Fambrini, G.L., Neumann, V.H.M.L., Silva Filho, W.F., Tesser Junior, S., Valença, L.M.M., Lima-Filho, M.F., Araújo, J.T., Souza B.Y.C., Lemos D.R. 2008. Eventos de subsidência e instalação de sistemas lacustres na Bacia do Araripe, Nordeste do Brasil. In: Congresso Brasileiro de Geologia, 44, 2008, Curitiba, PR, Anais(...). p. 118.

Fambrini, G.L., Tesser Jr., S., Neumann V.H.M.L., Souza B.Y.C., Silva Filho, W.F. 2009. Fácies e sistemas deposicionais na área-tipo da Formação Missão Velha, Bacia do Araripe, CE. Estudos Geológicos (UFPE), 19(1): 163-191.

Fambrini, G.L., Neumann, V.H.M.L., Lemos, D.R., Araújo, J.T., Lima-Filho, M.F. \& Silva-Filho, W.F. 2010a. 
Stratigraphy and sedimentology of the Rift Initiation to Rift Climax stages of the Araripe Basin, Northeastern Brazil: new considerations. In International Sedimentology Congress, 18., Abstracts Volume, pp. 333. IAS/PETROBRAS, Mendoza, Argentina. CD-ROM.

Fambrini, G.L.; Neumann, V.H.M.L.; Lemos, D.R.; Araújo, J.T.; Lima-Filho, M.F. \& Tesser Jr, S. 2010b. Facies and architectural elements of Missão Velha Formation (Upper JurassicEocretaceous), Araripe Basin, Northeastern Brazil. In International Sedimentology Congress, 18., Abstracts, pp. 332. IAS/PETROBRAS, Mendoza, Argentina. CD-ROM.

Fambrini, G.L.; Tesser Jr., S.; Neumann V.H.M.L.; Souza B.Y.C.; Silva-Filho, W.F.; Araújo J.T.; Lemos D.R. 2010c. Sedimentary fácies analysis and depositional systems of Missão Velha Formation in the type-area, Araripe Basin, northeastern Brazil: reservoir implications. In: Rio Oil \& Gas Expo and Conference 2010, Rio de Janeiro, RJ. Anais. 10 p.

Fambrini, G.L., Lemos, D.R., Tesser Junior., S., Araújo, J.T., Silva Filho, W.F., Souza, B.Y.C., Neumann, V.H.M.L. 2011. Estratigrafia, Arquitetura Deposicional e Faciologia da Formação Missão Velha (Neojurássico-Eocretáceo) na ÁreaTipo, Bacia do Araripe, Nordeste do Brasil: exemplo de sedimentação de Estágio de Início de Rifte a Clímax de Rifte. Geologia USP - Série Científica, 11(2): 55-87. http://dx.doi.org/10.5327/Z1519874X2011000200004

Fambrini, G.L; Batista Z.V., Neumann V.H.M.L., Valença, L.M.M.; Agostinho, S.M., Menezes-Filho, J.A.B. 2013a. Sedimentary fácies analysis of Cariri Formation, Sineclysis stage, Araripe Basin, Northeast Brazil. In: $6^{\text {th }}$ Latin American Congress of Sedimentology (6lacs), 2013, São Paulo SP. Abstracts of $6^{\text {th }}$ Latin
American Congress of Sedimentology, 2013. v. único.

Fambrini, G.L.; Neumann, V.H.M.L.; Barros, C.L.; Galm, P.C.; Agostinho, S.M.; Araújo J.T.; Menezes-Filho, J.A.B.. 2013b. Análise estratigráfica da Formação Brejo Santo, Bacia do Araripe, Nordeste do Brasil: implicações paleogeográficas. Geologia USP, Série Científica., vol. 13, n.4, pp. 3-28. https://doi.org/10.5327/Z1519874X201300040001

Fambrini, G.L., Neumann V.H.M.L., Buarque, B.V., Menezes-Filho, J.A.B., Silva-Filho, W.F. 2013c. Fácies and depositional systems of Missão Velha Formation (NeojurassicEocretaceous), Araripe Basin, Northeast Brazil: paleogeographic and tectonic implications. 6th Latin American Sedimentological Congress, 2013, São Paulo, Proceedings, p. 25, CD-ROM.

Fambrini, G.L., Oliveira, E. V., Neumann V.H.M.L., Buarque, B. V., Silva-Filho, W.F. 2013d. Sedimentological and stratigraphic implications of fossil woods from the Missão Velha Formation (NeojurassicEocretaceous), Araripe Basin, Northeast Brazil. 6th Latin American Sedimentological Congress, 2013, São Paulo, Brazil, Proceedings, p. 25, CDROM.

Fambrini, G.L., Neumann, V.H.M.L., Menezes Filho, J.A.B., Silva Filho, W.F., Oliveira, E.V. 2017. Facies architecture of the fluvial Missão Velha Formation (Late Jurassic-Early Cretaceous), Araripe Basin, Northeast Brazil: paleogeographic and tectonic implications. Acta Geologica Polonica, 67(4):

515-545. https://doi.org/10.1515/agp-2017-0029

Fambrini, G.L.; Silvestre, D.C.; MenezesFilho, J.A.B.; Costa, I.C., Neumann, V.H.M.L. 2019. Architectural and facies characterization of the Aptian fluvial Barbalha Formation, Araripe Basin, Northeastern Brazil. In: 
CORBETT, P. W. M., OWEN, A., HARTLEY, A. J., PLA-PUEYO, S., BARRETO, D., HACKNEY, C. \& KAPE, S. J. (eds) River to Reservoir: Geoscience to Engineering. Geological Society, London, Special Publications, 488, 119-150. https://doi.org/10.1144 /SP488-2017-275

Freitas, F.I., Hessel, M.H. Nogueira Neto, J.A. 2008. Troncos fósseis da Formação Missão Velha na porção leste da Bacia do Araripe, Ceará. Revista de Geologia, 21(2): 193-206.

Gaspary, J., Anjos, N.F.R. 1964. Estudo Hidrogeológico de Juazeiro do Norte Ceará. Recife, SUDENE. 25 p.

Ghignone, J.I., Couto, E.A., Assine, M.L. 1986. Estratigrafia e estrutura das Bacias do Araripe, Iguatu e Rio do Peixe. In: Congresso Brasileiro de Geologia, 34. Goiânia, 1986. Anais(...), Goiânia, SBG, p. 271-285.

Hartt, C.F., Agassiz, L. 1870. Geology and physical geography of Brazil. Boston, Osgood \& Co., 620p.

Hashimoto, A.T., Appi, C.J., Soldan, A.L., Cerqueira, J.R. 1987. O neo-Alagoas nas Bacias do Ceará, Araripe e Potiguar (Brasil): caracterização estratigráfica e paleoambiental. Revista Brasileira de Geociências, 17(2): 118-122.

Köppen, W. 1936. Das geographishe system der Klimate. In: Köppen, W.; Geiger, H. (Org.), Handbuch der Klimatologie. 1 ed. Berlim, Gebrüder Bomtrager, 1936, $44 \mathrm{p}$.

Kuchle, J., Scherer, C.M.S., Born, C.C., Alvarenga, R.S., Adegas, F.A. 2011. Contribution to Regional Stratigraphic Correlations of the Afro-Brazilian Depression - the Dom João Stage (Brotas Group and equivalent units Late Jurassic) in northeastern Brazilian sedimentary basins. Journal South American Earth Sciences, 31:358-371. https://doi.org/10.1016/j.jsames.2011. 02.007

Kurzawe, F., Merlotti, S. 2009. O complexo Dadoxylon-Araucarioxylon,

Carbonífero e Permiano do Gondwana: estudo taxonômico do gênero
Dadoxylon. Pesquisas em Geociências, 36(2): 223-232. https://doi.org/ 10.22456/1807-9806.17720

Lima, M.R. 1978. Estudo palinológico preliminar de um folhelho betuminoso da Formação Missão Velha, Chapada do Araripe. Boletim IG-USP, 9: 136139.

Lima, M.R. 1979. Considerações sobre a subdivisão estratigráfica da Formação Santana - Cretáceo do Nordeste do Brasil. Revista Brasileira de Geociências, 9(2): 116-121.

Mabesoone, J.M., Tinoco, I.M. 1973. Paleoecology of Aptian Santana Formation (Northeastern Brazil). Palaeogeography, Palaeoclimatology, Paleaeocolog,y 14(2): 87-118. https://doi.org/10.1016/00310182(73)90006-0

Maisey, J. G. 2000. Continental break up and the distribution of fishes of Western Gondwana during the Early Cretaceous. Cretaceous Research, 21(2-3): 281-314. https://doi.org/10.1006/cres.1999.0195

Martill, D. M. 1993. Fossil of the Santana and Crato formations, Brazil. Paleontological Association, Field Guide to Fossils, n. 5, 159 p.

Matos, R.M.D. 1992. The Northeast Brazilian rift system. Tectonics, 11(4): 766-791. https://doi.org/10.1029/91TC03092

Matos, R.M.D. 1999. History of the northeast Brazilian rift systen: kinemayic implications for the breakup between Brazil and West Africa. In: Cameron, N., Bate, R., Clure, V., Benton, J. (Org.), The oil and gas habitats of the South Atlantic. Londres, Geological Society of London Special Publication, p. 55-73.

McNeill, J., Barrie, F.R., Burdet, H.M., Demoulin, V., Hawksworth, D.L., Marhold, K., Nicolson, D.H., Prado, J., Silva, P.C., Skog, J.E., Wiersema, J.H. \& Turland, N.J. 2006. Código Internacional de Nomenclatura Botânica (Código de Viena). Adotado pelo XVII Congresso Internacional de 
Botânica, Viena, Áustria, julho de 2005. 181p. (Traduzido por C.E.M. Bicudo \& J. Prado).

Miall, A.D. 1978. Lithofacies types and vertical profile models in braidedrivers deposits: a summary. In: Miall, A.D. (Org.), Fluvial Sedimentology. Calgary, Canadian Society of Petroleum Geologists. p. 597-604.

Miall, A.D. 1996. The geology of fluvial deposits: sedimentary facies, basin analysis and petroleum geology. 1 ed. Berlim, Springer, $582 \mathrm{p}$.

Moraes, J.F.S., Santos, J.S., Mascarenhas, J.C. 1976. Projeto Santana. Etapa I. Recife, DNPM/CPRM, 269 p.

Morley, C.K. 2002. Evolution of large normal faults: Evidence from seismic reflection data. The American Association of Petroleum Geologists Bulletim, 86: 961-978. http://doi.org/10.1306/61EEDBFC173E-11D7-8645000102C1865D

Mussa, D. 1959. Contribuição à paleoanatomia vegetal: I - Madeira fóssil do Cretáceo de Sergipe. Notas Preliminares e Estudos, Rio de Janeiro, DNPM. 15 p.

Neumann, V.H.M.L. 1999. Estratigrafía, sedimentología, geoquímica y diagénesis de los sistemas lacustres aptienses-albienses de la Cuenca de Araripe (Noreste de Brasil). Tese (Doutorado em Geologia) - Facultad de Ciencias de la Tierra, Universidad de Barcelona, Barcelona, 244p.

Neumann, V.H.M.L., Cabrera, L. 2000. Significance and genetic interpretation of the sequential organization of the Aptian-Albian lacustrine system of the Araripe Basin. Anais da Academia Brasileira de Ciências, 72(4): 607-608. http://dx.doi.org/10.1590/S0001$\underline{37652000000400030}$

Petri, S. 1987. Cretaceous paleogeographic maps of Brazil. Palaeogeography, Palaeoclimatology, Palaeoecology, 59(1): 117-168. https://doi.org/10. 1016/0031-0182(87)90077-0

Philippe, M. 1993. Nomenclature générique des trachéidoxyles fossiles mésozoïques à champs araucarioïdes.

Taxon,

42:

74-80.

https://doi.org/10.2307/1223305

Pires, E.F., Guerra-Sommer, M. 2011. Growth ring analysis of fossil coniferous woods from early cretaceous of Araripe Basin (Brazil). Anais da Academia Brasileira de Ciências, $\quad$ 83(2): 409-423. http://dx.doi.org/10.1590/S000137652011005000005

Ponte, F.C., Asmus, H.E. 1976. The Brazilian marginal basins: current state of knowledge. Anais da Academia Brasileira de Ciências, 48: 215-239.

Ponte, F.C., Asmus, H.E. 1978. Geological framework of the Brazilian continental margin. Geologische Rundschau, 67: 201-235.

Ponte, F.C.; Appi, C.J. 1990. Proposta de revisão da coluna litoestratigráfica da Bacia do Araripe. In: Congresso Brasileiro de Geologia, 36. Natal, 1990. Anais(...), Natal, SBG, p. 211226.

Ponte, F.C., Arai, M., Dino, R., SilvaTelles, A.C. 1990. Estratigrafia comparada das bacias sedimentares mesozóicas do interior do Nordeste do Brasil: uma síntese. In: Simpósio sobre as bacias cretáceas brasileiras, 1. Rio Claro, 1990. Boletim de Resumos(...), Rio Claro, UNESP/IGCE, p. 61-64.

Ponte, F.C., Ponte-Filho, F.C. 1996. Estrutura geológica e evolução tectônica da Bacia do Araripe. Recife, DNPM/DMME, $68 \mathrm{p}$.

Prosser, S. 1993. Rift-related Linked Depositional Systems and Their Seismic Expression. Geological Society of London - Special Publications 71(1): 35-66. https://doi.org/10.1144/GSL.SP.1993. $\underline{071.01 .03}$

Santos, E.J.; Nutman, A.P.; Brito-Neves, B.B. 2004. Idades SHRIMP U-Pb do Complexo Sertânia: implicações sobre a evolução tectônica da Zona Transversal, Província Borborema. Geologia USP. Série Científica, São Paulo (SP), v. 4, n. 1, p. 1-12, 2004. 
http://dx.doi.org/10.5327/s1519-

874x2004000100001

Scherer, C.M.S., Lavina, E.L.C., Dias Filho, D.C., Oliveira, F.M., Bongiolo, D.E., Aguiar, E.S. 2007. Stratigraphy and facies architecture of the fluvialaeolian-lacustrine Sergi Formation (Upper Jurassic), Recôncavo Basin, Brazil. Sedimentary Geology, 194: 169-193.

https://doi.org/10.1016/j.sedgeo.2006. 06.002

Scherer, C.M.S., Jardim de Sá, E.F., Córdoba, V.C., Sousa, D.C., Aquino, M.M., Cardoso, F.M.C. 2014. Tectonostratigraphic evolution of Upper Jurassic-Neocomian rift succession, Araripe Basin, Northeast Brazil. Journal of South American Earth Sciences, 49: 106-122. https://doi.org/10.1016/j.jsames.2013. 10.007

Silva, M.A.M. 1983. The Araripe Basin, Northeastern Brazil: Regional Geology and Facies Analysis of a Lower Cretaceous Evaporitic Depositional Complex. Tese (Doutorado em Geologia) - Department of Earth and Environmental Sciences, Columbia University, Nova York, 290 p.

Silva, M.A.M. 1986. Lower Cretaceous sedimentary sequences in the Araripe Basin, Northeastern Brazil: a revision. Revista Brasileira de Geociências, 16(3): 311-319.

Silva Filho, W.F., Ferreira, L.A.N., Barreto Junior, A.M., Nogueira Neto, J.A. 2015. Representações da pedra-pau e do Geopark Araripe na área do Geossítio Floresta Petrificada do Cariri, Milagres - Ceará. In: Simpósio Brasileiro De Patrimônio Geológico, 3. Lençóis, 2015. Anais(...), Lençóis, UEFS, p. 336-339.

Silveira, A.C., Silva, A.C., Cabral, N.R.A.J., Schiavetti, A. 2012. Análise de efetividade de manejo do Geopark Araripe - Estado do Ceará. Geociências, 31(1): 117-128.

Silvestre, D.C., Fambrini, G.L., Santos, A.A.F. 2017. Caracterização
Faciológica das Formações Cariri e Brejo Santo em afloramentos a NE do Município Missão Velha (Ceará Brasil). Estudos Geológicos, 27(1): 1933. https://doi.org/10.18190/19808208/estudosgeologicos.v27n1p19-33

Sousa-Brasil, T.P. 1863. Ensaio estatístico da província do Ceará. São Luiz, Typographia de B. de Mattos, 839 p.

Small, H. 1913. Geologia e Suprimento de Água Subterrânea no Piauhy e Parte do Ceará. Recife, IOCS, 80 p.

Toledo, C.E.V., Bertini, R.J. 2005. Occurrences of the fóssil dipnoiformes in Brazil and its stratigraphic and chronological distributions. Revista Brasileira de Paleontologia, 8(1): 4756.

Valença, L.M.M., Neumann, V.H.M.L., Mabesoone, J.M. 2003. An overview on Callovian-Cenomanian intracratonic basins of Northeastern Brazil: onshore stratigraphic record of the opening of the southern Atlantic. Geologica Acta, 1(3): 261-275. https://doi.org/10.1344/105.00000161 $\underline{4}$

Viana, C.F. 1980. Cronoestratigrafia dos sedimentos da margem continental brasileira. In: Congresso Brasileiro de Geologia, 31. Balneário do Camboriú, 1980. Anais(...), Balneário do Camboriú, SBG, p. 832-843.

Viana, M.S.S., Cavalcanti, V.M.M. 1989. Faciologia das formações Missão Velha e Brejo Santo na região de Missão Velha, Ceará In: Simpósio de Geologia do Nordeste, 13, Fortaleza, 1989. Anais(...), Fortaleza, SBGNúcleo Nordeste, p. 166-169. 